\section{TÀI LIÊU THAM KHẢO}

1. Wang H., Naghavi M., Allen C., et al. (2016), "Global, regional, and national life expectancy, allcause mortality, and cause-specific mortality for 249 causes of death, 1980-2015: a systematic analysis for the Global Burden of Disease Study 2015", The Lancet, 388(10053), 1459-1544.

2. Benjamin EJ., Blaha MJ., Chiuve SE., et al. (2017), "Heart disease and stroke statistics-2017 update: a report from the American Heart Association", circulation, 135(10), e146-e603.

3. Kristian Thygesen, Joseph S. Alpert, Allan S. Jaffe, et al. (2012), "Third Universal Definition of Myocardial Infarction", Circulation, 126, 2020-2035.

4. Kim HL., Kim SH. (2019), "Pulse wave velocity in atherosclerosis", Frontiers in cardiovascular medicine, 6, 41.

5. Myslinski W., Stanek A., Feldo M., et al. (2020), "Ankle-brachial index as the best predictor of first acute coronary syndrome in patients with treated systemic hypertension", BioMed Research International, 2020.
6. Koji Y., Tomiyama $H_{.,}$Ichihashi $H_{.,}$et al. (2004), "Comparison of ankle-brachial pressure index and pulse wave velocity as markers of the presence of coronary artery disease in subjects with a high risk of atherosclerotic cardiovascular disease", Am J Cardiol, 94(7), 868-72.

7. Alarhabi A.Y., et al. (2009), "Pulse Wave Velocity as a marker of severity of coronary artery disease" J Clin Hypertens (Greenwich): 17-21.

8. Linh Phan Đồng Bảo (2013), Nghiên cứu đăc điểm tổn thương mạch vành và vận tốc sóng mach ở bệnh nhân tăng huyết áp nguyên phát có bệnh mach vành; Đai học y dược Huế, Bộ y tế.

9. Chung CM., Ṫseng Y., Lin YS., et al. (2015), "Association of brachial-ankle pulse wave velocity with atherosclerosis and presence of coronary artery disease in older patients", Clinical interventions in aging, 10, 1369.

10. Zhang F., Liu J., Huang W., et al. (2013), "Associations of SYNTAX score with serum homocysteine and brachial-ankle pulse wave velocity []]", Journal of Chinese Practical Diagnosis and Therapy, 2.

\title{
ĐẶC ĐIỂM LÂM SÀNG, CÂ̂N LÂM SÀNG VÀ HIỆU QUẢ ĐIỀU TRI THOÁT VI ĐĨA ĐÊM CộT SỐNG THẮT LƯNG BẰNG TIÊM HYDROCORTISON NGOÀI MÀNG CỨNG
}

\section{TÓM TẮT.}

Mục tiêu: Mô tả đăc điểm lâm sàng, cận lâm sàng và đánh giá kết quả điều trị thoát vị đĩa đệm cột sống thắt lưng bằng phương pháp tiêm Hydrocortison ngoài màng cứng. Phương pháp: Nghiên cứu can thiệp trên 80 bênh nhân được chẩn đoán thoát vị đĩa đệm cột sống thắt lưng điều trị tại khoa Thần kinh Bệnh viền Hữu nghi Đa khoa Nghể An năm 2020 - 2021. Kết quả: Tuổi đối tượng nghiên cứu từ $27-86$ tuổi, độ tuổi $30-60$ tuổi chiếm 57,5\%, >60 tuôir chiếm $38,7 \%,<30$ tuổi chiếm 3,8\%. Nữ giới $62,5 \%$, nam giới $37,5 \%$. Nghề nghiệp lao động chân tay chiếm 68,8\%, lao động trí óc 28,8\%. Đặc điểm lâm sàng: Hội chứng cột sống (hạn chế tầm hoạt động CSTL 96,2\%, điểm đau CSTL 91,2\%, giảm chỉ số Schober < $14 / 10 \mathrm{~cm} 88,8 \% \ldots)$ và hội chứng chèn ép rễ thần kinh (dấu hiệu Lasègue (+) 95\%, dấu hiệu 'Chuông bấm' (+) $91,2 \% \ldots)$; về cận lâm sàng: loại thoát vị lồi đĩa đệm 41,2\%, L4 - L5 61,2\%. Sau điêu trị tiêm Hydrocortison ngoài màng cứng, các dấu hiệu giảm rõ rệt. Tỷ lệ điều trị thành công cao chiếm 97,5\%, chuyển phẫu thuật 2,5\%. Kết luận: Nghiên cứu cho thấy tiêm hydrocortisol ngoài màng cứng cải thiện có

${ }^{1}$ Trường Đại học Y khoa Vinh

Chịu trách nhiệm chính: Nguyễn Văn Tuấn

Email: tuanminh1976@gmail.com

Ngày nhận bài: 16.9.2021

Ngày phản biên khoa hoc: 12.11.2021

Ngày duyệt bài: 23.11.2021

\section{Nguyễn Văn Tuấn ${ }^{1}$, Nguyễn Anh Dũng ${ }^{1}$}

ý nghĩa thống kê các triệu chứng lâm sàng ở bệnh nhân thoát vị đĩa đệm cột sống thắt lưng.

Tư khóa: Thoát vị đĩa đệm cột sống thắt lưng, tiêm hydrocortisone ngoài màng cứng.

\section{SUMMARY \\ CLINICAL, PARACLINICAL FEATURES AND EVALUATION OF THE EFFECTIVENESS OF TREATMENT OF LUMBAR DISC HERNIATION WITH EPIDURAL HYDROCORTISONE INJECTION}

Objectives: To describe clinical and paraclinical characteristics; to remark on the outcomes of treatment of lumbar disc herniation with epidural hydrocortisone injection. Methods: Intervention study was conducted on 80 patients who were diagnosed with lumbar disc herniation at the Neurology Department of Nghe An General Hospital in 2020 - 2021. Results: The age of the study subjects was from 27 to 86 , the age from 30 to 60 accounted for $57.5 \%$, over $>60$ accounted for $38.7 \%$, under $<30$ accounted for $3.8 \%$. Female $62.5 \%$, male $37.5 \%$. Occupation of manual labor accounted for $68.8 \%$, mental labor $28.8 \% \ldots$ Clinical features: Spine syndrome (limited range of physical activity $96.2 \%$, pain score $91.2 \%$, decrease in Schober index $<14 / 10$ $\mathrm{cm} 88.8 \% \ldots)$ and nerve root compression syndrome (Lasègue sign (+) 95\%, 'Bell' sign" (+) +) 91.2\%...); on paraclinical: herniated disc type $41.2 \%$, L4 - L5 $61.2 \%$. After treatment with epidural hydrocortisone 
injection, the signs decreased markedly. The success rate of treatment is high, accounting for $97.5 \%$, conversion to surgery is $2.5 \%$. Conclusion: The study showed that epidural hydrocortisone injection significantly improved the clinical symptoms in patients with lumbar disc herniation.

Keywords: Lumbar disc herniation, epidural hydrocortisone injection

\section{I. ĐẶT VẤN ĐỀ}

Thoát vị đĩa đệm cột sống thắt lưng là bệnh thường gặp, đóng vai trò quan trọng trong bệnh căn của hội chứng thắt lưng hông. Bệnh khổng gây nguy hiểm đến tính mạng nhưng dẫn đến đau thắt lưng mạn tính hoặc cấp tính, làm giảm khả năng thích ứng của cột sống [1]. Dâu hiệu lâm sàng của thoát vị đĩa đệm cột sống thắt lưng được thể hiện bằng hai hội chứng chính: hội chứng cột sống và hội chứng rể thần kinh [3],[6]. Bệnh gây ảnh hưởng lớn đến năng suất lao động và chất lượng cuộc sống, là một trong những nguyên nhân gây nghỉ việc lớn nhất ở Việt Nam và trên thế giới. Bệnh có thể được điều trị bằng 3 phương pháp: bảo tồn, can thiệp tối thiểu và phẫu thuật. Phương pháp điều trị tiêm steroid ngoài màng cứng được tiến hành từ những năm 1960 - 1970 trên thế giới [1].

Tại Việt Nam, phương pháp này đã áp dụng rộng rãi ở các bệnh viện trong nước, có chuyên khoa thần kinh và đã được xây dựng thành quy trình kỹ thuật được thực hiện có tỷ lệ thành công cao và an toàn. Ớ Nghệ An chưa có báo cáo nào về đánh giá hiệu quả sử dụng hydrocortisone trong điêu trị can thiệp tối thiểu ở bệnh nhân thoát vị đĩa đệm cột sống thắt lưng. Vì vậy chúng tôi nghiên cứu đề tài này nhằm mục tiêu: Mô tả đặc điểm lâm sàng, cận lâm sàng; đánh giá kêt quả điều trị thoát vị đía đệm cột sông thắt lưng bằng phương pháp tiêm Hydrocortison ngoài màng cứng.

\section{II. ĐỐI TƯỢNG VÀ PHƯƠNG PHÁP NGHIÊN CỨU \\ 2.1. Đối tượng nghiên cứu \\ 2.1.1 Tiêu chuẩn lựa chọn}

- Bênh nhân được chẩn đoán thoát vị đĩa đệm cột sống thắt lưng được điều trị bằng tiêm 3 mũi hydrocortisone ngoài màng cứng, các mũi tiêm cách nhau 3 ngày.

- Tất cả bệnh nhân được chụp cộng hưởng từ có hình ảnh thoát vị đĩa đệm cột sống thắt lung.

\subsubsection{Tiêu chuân loại trừ}

- Bệnh nhân đã được điều trị phẫu thuật thoát vị đĩa đệm cột sống thắt lưng được điều trị bằng các phương pháp pháp can thiệp giảm áp đĩa đệm trước đó.

- Bệnh nhân bị chống chỉ định của thuốc và phương pháp điều trị tiêm hydrocortisone ngào màng cứng.

- Bệnh nhân có các bệnh lý kết hợp như chấn thương cột sống, bệnh lý tủy sống, lao cột sống, ung thư cột sống, ...

- Bệnh nhân không đồng ý tham gia nghiêu cứu.

\subsection{Phương pháp nghiên cứu}

2.2.1. Thiết kế nghiên cứu. Nghiên cứu can thiệp so sánh trước sau

2.2.2. Thời gian và địa điểm nghiên cứu. Nghiên cứu được thực hiện tại khoa Thần kinh Bệnh viện Hữu nghị Đa khoa Nghệ An từ tháng 11/2020 đến 05/2021.

\subsubsection{Cỡ mấu và phương pháp chọn mẫu}

- Cỡ mẫu: 80 bệnh nhân

- Phương pháp chọn mẫu: Chọn mẫu thuận tiện những bệnh nhân đủ tiêu chuẩn lựa chọn và tiểu chuẩn loại trừ để đưa vào nghiên cứu.

\subsection{Các tiêu chuẩn áp dụng trong} nghiên cứu

2.3.1. Tiêu chuẩn chẩn đoán xác định thoát vị đĩa đệm cột sống thắt lưng [2]

- Lâm sàng: Bệnh nhân có 4 triệu chứng trở lên trong số 6 triệu chứng sau:

+ Có yếu tố chấn thương

+ Đau cột sống thắt lưng lan theo rễ, dây thần kinh hông to.

+ Đau tăng khi ho, hắt hơi, rặn.

+ Có tư thế giảm đau, nghiêng người về một bên làm cột sống thắt lung bị vẹo.

+ Có dấu hiệu chuông bấm.

+ Dấu hiệu Lasegue (+)

- Cận lâm sàng: X-quang thường quy có tam chứng Barr, chụp bao rễ cản quang có hình ảnh chèn ép, chụp cộng hưởng từ thấy rõ hình ảnh đĩa đệm thoát vị.

2.3.2. Tiêu chuẩn đánh giá mức độ đau theo thang điểm VAS [7]: Thang điểm VAS là thang điểm đánh giá cường độ đau theo cảm giác chủ quan của bệnh nhân tại thờ điểm nghiên cứu được lượng hóa. Từ 0 đến 3 điểm: đau nhẹ; từ 3 đến 7 điểm: đau vừa và từ 7 đến 10 điểm: đau nặng

2.4. Xử lý số liệu: - Số liệu được xử lý bằng phần mềm SPSS 20.0.

- Sử dụng test X2 để so sánh sự khác biệt về tỷ lệ phần trăm. 0,05 


\section{KẾT QUẢ NGHIÊN CỨU}

Bảng 1. Triệu chứng đau lưng và vị trí tầng thoát vị đià đệm dựa vào cộng hưởng từ ( $n=80$ )

\begin{tabular}{|c|c|c|c|}
\hline \multicolumn{2}{|r|}{ Đau do thoát vị đĩa đệm } & n & $\%$ \\
\hline \multirow{3}{*}{ Mức độ } & Không ảnh hưởng đến công việc & 13 & 16,2 \\
\hline & Ánh hưởng đến công việc & 39 & 48,8 \\
\hline & Phải nghỉ làm & 28 & 35,0 \\
\hline \multirow{3}{*}{ Điểm đau VAS } & Nhẹ: 0 - 3 điểm & 10 & 12,5 \\
\hline & Vừa: 4 - < 7 điếm & 44 & 55 \\
\hline & Nặng: 7 - 10 điếm & 26 & 32,5 \\
\hline \multirow{3}{*}{ Vị trí } & Tại chô CSTL & 7 & 8,8 \\
\hline & Tại chô và lan xuống mông, đùi & 33 & 41,2 \\
\hline & Tại chồ và lan xuống mông, đùi, cắng chân & 40 & 50,0 \\
\hline Có tính chất cơ học & Đi lại, vận động làm việc đau tăng. Giảm khi nằm, nghỉ & 66 & 82,5 \\
\hline \multirow{5}{*}{$\begin{array}{c}\text { Vị trí tâng đĩa đệm } \\
\text { thoát vị }\end{array}$} & L1-L2 & 2 & 2,5 \\
\hline & L2-L3 & 8 & 10,0 \\
\hline & L3-L4 & 24 & 30,0 \\
\hline & L4-L5 & 49 & 61,2 \\
\hline & L5-S1 & 33 & 41,2 \\
\hline
\end{tabular}

Nhận xét: Đau lưng ảnh hưởng đến công việc chiếm 51,4\%; phải nghỉ làm chiếm 35\%. Đau vừa và nặng lượng giá theo điểm VAS $87,5 \%$. Đau lan xuống mông, đùi, cẳng chân chiếm nhiều nhất $50 \% .82,5 \%$ đau có tính chất cơ học. Vị trí tầng thoát vị thường gặp dựa vào hình ảnh cộng hưởng từ L4 - L5 61,2\% và L5 - S1 41,2\%.

Bảng 2. Mức độ giảm đau đánh giá theo thang điểm VAS $(n=80)$

\begin{tabular}{|c|c|c|c|c|c|}
\hline \multirow{2}{*}{ Điểm đau VAS } & \multicolumn{2}{|c|}{ Trước điều trị } & \multicolumn{2}{c|}{ Sau điều trị } & \multirow{2}{*}{$\mathrm{p}$} \\
\cline { 2 - 5 } & $\mathbf{n}$ & $\mathbf{\%}$ & $\mathbf{n}$ & $\mathbf{\%}$ & \\
\hline Nhẹ: $0-3$ điếm & 10 & 12,5 & 65 & 81,2 & \multirow{2}{*}{$<0,05$} \\
\hline Vừa: $4-6$ điếm & 44 & 55 & 14 & 17,5 & \\
\hline Nặng: $7-10$ điểm & 26 & 32,5 & 1 & 1,2 & \\
\hline
\end{tabular}

Nhận xét: Trước điều trị đau mức độ vừa và nặng chiếm tỷ lệ cao $55 \%$ và $32,5 \%$. Sau điều trị còn 1 trường hợp đau nặng với 1,2\% và mức độ đau nhẹ chiếm tỷ lệ cao $81,2 \%$.

Bảng 3. Các dấu hiệu của hội chứng cột sống $(n=80)$

\begin{tabular}{|c|c|c|c|c|c|}
\hline \multirow{2}{*}{ Dấu hiệu của cột sống } & \multicolumn{2}{|c|}{ Trước điếu trị } & \multicolumn{2}{|c|}{ Sau điều trị } & \multirow{2}{*}{ p } \\
\cline { 2 - 5 } & $\mathbf{n}$ & $\mathbf{\%}$ & $\mathbf{n}$ & $\mathbf{\%}$ & $<0,01$ \\
\hline Điếm đau CSTL & 73 & 91,2 & 8 & 10,0 & $<0,01$ \\
\hline Co cứng Cớ cạnh sống & 54 & 67,5 & 4 & 5,0 & $<0,05$ \\
\hline Lệch vẹo CSTL & 12 & 15,0 & 3 & 3,8 & $<0,05$ \\
\hline Giảm, mất ưỡn sinh lý CSTL & 23 & 28,8 & 3 & 3,8 & $<0,05$ \\
\hline Hạn chễ tầm hoạt động CSTL & 77 & 96,2 & 7 & 8,9 & $<0,01$ \\
\hline Giảm chîn số Schober < 14/10 cm & 71 & 88,8 & 10 & 12,5 & $<0,01$ \\
\hline
\end{tabular}

Nhận xét: Với phương pháp điều trị này các triệu chứng cột sống giảm rõ

Bảng 4. Dâu hiệu Lasègue $(+)$ trước và sau điêuu trị bảo tồn $(n=80)$

\begin{tabular}{|c|c|c|c|c|c|}
\hline \multirow{2}{*}{ Dấu hiệu Lasègue } & \multicolumn{2}{|c|}{ Trước điếu trị } & \multicolumn{2}{|c|}{ Sau điều tri } & \multirow{2}{*}{ p } \\
\cline { 2 - 5 } & $\mathbf{n}$ & $\mathbf{\%}$ & $\mathbf{n}$ & \\
\hline Rất tốt $>80$ độ & 17 & 21,1 & 56 & 71,1 & \\
\hline Tốt $60-80$ độ̀ & 24 & 30,2 & 19 & 22,3 & \multirow{2}{*}{$<0,05$} \\
\hline Trung bình $30-60$ độ & 28 & 35,5 & 3 & 4,0 & \\
\hline Không kết quả <30 độn & 11 & 13,2 & 2 & 2,6 & \\
\hline
\end{tabular}

Nhân xét: Trước điều trị dấu hiệu Laségue $<80$ o chiếm 78,9\%, $>80$ o chiếm $21,1 \%$. Sau điều trị Laségue $>80$ o chiếm $71,1 \%,<80$ o chiếm $28,9 \%$.

Bảng 5. Hiệu quả điều trị và tỷ lệ bệnh nhân chuyển điều trị phẫu thuật $(n=80)$

\begin{tabular}{|c|c|c|}
\hline Kết quả điều trị & Số bệnh nhân & Tỷ lệ \% \\
\hline Eiều trị có kết quả & 78 & 97,5 \\
\hline Chuyến phâu thuật & 2 & 2,5 \\
\hline Tổng & $\mathbf{8 0}$ & $\mathbf{1 0 0}$ \\
\hline
\end{tabular}


Nhận xét: Tỷ lệ điều trị thành công cao chiếm $97,5 \%$, chuyển phẫu thuật 2,5\%.

\section{BÀN LUÂ̂N}

Nhóm bệnh nhân nghiên cứu có đô tuổi từ 27 đến 86 , trong đó nhóm tuổi $<30$ chiếm tỷ lệ là $3,8 \%$, nhóm tuổi từ 30 đến 60 chiếm $57,5 \%$, nhóm tuổi $>60$ chiếm $11,2 \%$. Thường gắp ở những đối tượng trong thời kỳ lao động, đây là thời kỳ con người làm việc nhiều và nặng nhất, có tác động lớn đến chức năng cột sông, đặc biệt là cột sống thắt lưng. Kết quả này tương đồng với Hoàng Văn Thuận (2018), 30 - 60 tuổi chiếm 67,7\% [5].

Nữ giới chiếm tỷ lệ ưu thế hơn so với nam giới, nữ là $62,5 \%$, nam là $37,5 \%$. Kết quả này tương đồng với Nguyễn Thị Thanh (2017) nữ chiếm tỷ lệ là $58,6 \%$, nam chiếm $41,4 \%$. Tuy nhiên, một số nghiên cứu lại cho thấy tỷ lệ nam mắc bệnh chiếm ưu thế rõ, Hà Kim Trung (2017) nam chiếm tới $82 \%$. Sự khác biệt về phân bố giới tính của tác giả trên có thể được giải thích qua địa lý vùng miền, tính chất nghề nghiệp và thời gian lao động của các đối tượng.

Trong tất cả đối tượng được nghiên cứu, đối tượng có khởi phát sau yếu tố cơ học như chấn thương, động tác tư thế bất thường chiếm tỷ lệ $26,2 \%$, không có yếu tố nguy cơ là $73,8 \%$; hoăc khởi phát mang tính chất đột ngột chiếm $30 \%$, từ từ là $70 \%$. Tỷ lệ này nói lên sự liên quan đến tính chất công việc, thói quen hoạt động và kết quả này cũng gần bằng với nhiều nghiên cứu trước như Nguyễn Văn Chương, Nguyễn Thị Hòa (2017), và nghiên cứu của Merel Wassenaar [9].

Chúng tôi sử dụng "Thang điểm trực quan tương ứng - VAS" để đánh giá cụ thể triệu chứng đau. Ưu điểm của phương pháp này là dễ sử dụng, dễ hiểu nên có được sư thuận lợi khi phối hợp giữa bệnh nhân và thầy thuốc. Hiện nay, thang điểm này được nhiều tác giả trong nước sử dụng. Kết quả điều trị qua bảng cho thấy điểm VAS giảm đi rõ rệt (trước điều trị mức độ nhẹ, vừa, nặng có tỷ lệ lần lượt là: $12,5 \%$, $55 \%, 32,5 \%$; sau điêu trị tỷ lệ là: $81,2 \%$, $17,5 \%, 1.2 \%)$. Tỷ lệ này phù hợp với nhiêu tác giả như Lê Văn Bình (2013), trước điêuu trị mức độ đau nhẹ, vừa, nặng lần lượt 14,5\%; 48,7\%; $37,8 \%$, sau điêu trị mức độ đau được cải thiện với tỷ lệ lần lượt $61,7 \% ; 18,6 \% ; 9,7 \%$.

Trong nghiển cứu của chúng tôi, kết quả qua thống kê nghiên cứu cho thấy: Điểm đau cột sông thắt lưng trước điều trị $91,2 \%$; sau điều trị $10 \%$; triệu chứng khỏi với $81,2 \%$. Co cứng cơ cạnh sống trước điều trị $67,5 \%$; sau điêu trị $5 \%$; triệu chứng khỏi với $62,5 \%$. Lệch vẹo cột sống thắt lưng trước điêu trị 15\%; sau điều trị 3,8\%; triệu chứng khỏi với $11,2 \%$. Giảm, mất ưỡn sinh lý cột sống thắt lưng trước điêu trị $28,8 \%$; sau điều trị 3,8\%; triệu chứng khỏi với $25 \%$. Hạn chế tầm hoạt động cột sống thắt lưng trước điều trị 96,2\%; sau điêu trị 8,9\%; triệu chứng khỏi với $87,3 \%$. Giảm chỉ số Schober $<14 / 10 \mathrm{~cm}$ trước điều trị $90 \%$; sau điêu trị 4,3\%; triệu chứng khỏi với $85,7 \%$. Các dấu hiệu lâm sàng được cải thiện rõ với triệu chứng khỏi tương đối cao. Kết quả này tương đồng với các nghiên cứu trong và ngoài nước trong việc điêu trị bằng phương pháp tiêm hydrocortisone ngoài màng cứng [4].

Trong nghiên cứu của chúng tôi, 80 bênh nhân trong nhóm nghiên cứu đã điều trị bằng phương pháp tiêm hydrocortison ngoài màng cứng đạt hiệu quả khi ra viện là $97,5 \%$. Phải chuyển phẫu thuật 2 bệnh nhẩn chiếm 2,5\%. Kết quả nghiên cứu của Nguyễn Thị Ngọc Lan (2019) tỷ lệ điều trị đau thần kinh tọa đạt hiệu quả 96/100 bệnh nhân chiếm $96 \%, 4 / 100$ bệnh nhân chuyển phẫu thuât chiếm 4\%. Lê Văn Bình (2013) có 19/180 bệnh nhân chuyển phẫu thuật chiếm 10,56\%. Điều trị phương pháp này kết hợp phục hồi chức năng, vật lý trị liệu trong các trường hợp ở giai đoạn nặng không đồng ý phẫu thuật cũng có tỷ lệ hiệu quả nhất định.

\section{KẾT LUẬN}

Nghiên cứu cho thây tiêm hydrocortisol ngoài màng cứng cải thiện có ý nghĩa thống kê các triệu chứng lâm sàng ở bệnh nhân thoát vị đĩa đệm cột sống thắt lưng.

\section{TÀI LIÊU THAM KHẢO}

1. Vũ Quang Bích (2006), "Phòng và điều trị bênh đau lưng". Nhà xuất bản Y hoc; . tr. 55-70.

2. Bố y tế (2016), "Hướng dần chẩn đoán và điều trị các bệnh cơ xương khởp". Nhà xuất bản Y học; tr. 131-144.

3. Ngô Quý Châu (2018), "Bệnh học Nội khoa". Trường Đại học $Y$ hà Nội, Nhà xuất bản Y học; tr. 252-270.

4. Nguyễn Văn Chương, Nguyễn Thị Hòa (2017), "Đánh giá hiệu quả điêu trị thoát vị đĩa đêm cốt sống thắt lưng của phác đồ tiêm ngoài màng cứng Methylprednisolon kết hợp với uống Cyclophosphorine A". Tạp chí Nội khoa Việt Nam. 2017;3:3-16.

5. Hoàng Văn Thuân (2018), "Nghiên cứu lâm sàng thoát vị đĩa đệm cột sông thắt lưng". Tạp chi $Y$ học thực hành ;27:11-3.

6. Hà Kim Trung '(2017), "Phẩu thuật thần kinh". Nhà xuất bản Y học; tr. 374-399 p.

7. Aletaha D., Smolen JS. (2018), "Diagnosis and Management of Rheumatoid Arthritis: A Review". JAMA. 2018 Oct; 320(13):1360-72.

8. Rogerson A, Aidlen J, Jenis LG (2019), "Persistent radiculopathy after surgical treatment 
for lumbar disc herniation: causes and treatment options". Int Orthop. 2019 Apr;43(4):969-73.

9. Wassenaar M, Van Rijn RM, Van Tulder MW, Verhagen AP, van der Windt DAWM, Koes BW, et al (2012), "Magnetic resonance imaging for diagnosing lumbar spinal pathology in adult patients with low back pain or sciatica: a diagnostic systematic review". Eur spine J Off Publ Eur Spine Soc Eur Spinal Deform Soc Eur Sect Cerv Spine Res Soc. 2012 Feb;21(2):220-7.

\title{
RỐI LOAN NHIPP TIM TRÊN HOLTER ĐIÊN TÂM ĐỒ 24 GIỜ Ở BỆNH NHÂN SUY THẬN ĐƯợC LỌC MÁU CHU KỲ TẠI BỆNH VIỆN BẠCH MAI
}

\author{
Sat Chanthy ${ }^{1}$, Trần Song Giang ${ }^{2}$, Nguyễn Hữu Dũng ${ }^{3}$
}

\section{TÓM TẮT}

Đă̆t vấn đề: Lọc máu chu kỳ ngày càng phổ biến do sổ lượng bệnh nhân suy thận tăng nhanh; tuy nhiên có nhiêu tai biến đặc biệt liền quan đến tî lệ rối loạn nhịp cao. Muc tiêu: Mô tả đặc điểm rối loạn nhịp tim và một số yếu tố liên quan ở bệnh nhân sưy thận được lọc máu chu kỳ tại bệnh viện Bạch Mai. Đối tượng \& phương pháp: 51 bệnh nhân suy thận đang loc máu tại bệnh viện Bạch Mai và không mắc bênh cấp tính. Kết quả: Tuổi trung bình là $54,4 \pm 12,7$ tuổi; tỉ lệ nữ cao hớn so với nam giới (58,8\% so với $41,2 \%)$; phần lớn có thời gian lọc máu 5-10 năm $(35,3 \%)$ và trên 10 năm $(35,3 \%)$. Tỉ lê rối loan nhip tim trên holter điện tâm đồ 24 giờ $(80,4 \%)$ : rối loạn nhip trên thất (NTi nhĩ đơn lẻ: $41,2 \%$; NTTnhĩ chùm đôi: 15,7\%, nhịp nhanh xoang $\geq 50 \%$ : 3,9\%, nhịp nhanh kịch phát trên thất: $5,8 \%$, cơn rung nhĩ: $9,8 \%$ ); rối loạn nhịp thất (NTT thất nhịp đôi: 11,8\%, nhịp ba: $7,8 \%$, đa dang, phức tap: $7,8 \%$, chùm đôi, chùm ba: 5,9\%, dạng R/T: 3,9\%, cơn nhịp nhanh thất không bền bỉ: $6,9 \%$ ). Tỉ lệ rối loan nhịp cao hơn ở nhóm có THA, ĐTĐ, thiếu máu. Kết luận: Tỉ lệ rối loạn nhịp cao ở bệnh nhân lọc máu chú kỳ có liên quan đển tăng huyết áp, thiếu máu và rối loạn điện giải.

Tư khóa: bệnh thận mạn, lọc máu chu kỳ, rối loạn nhịp, holter điện tâm đồ.

\section{SUMMARY}

ARRHYTHMIA IN HOLTER 24 HOUR IN END STAGE RENAL DISEASE PATIENTS ON HEMODIALYSISAT BACH MAI HOSPITAL

Background: Hemodialysis is popular of patients with renal failure; however, many adverse events are particularly associated with high rates of arrhythmias. Objectives: To describe the characteristics of heart rhythm disturbances and some related factors in renal failure patients undergoing dialysis at Bach Mai hospital. Subjects \& methods: 51 patients with

\footnotetext{
${ }^{1}$ Trường Đại học Y Hà Nội,

${ }^{2}$ Viên Tim mạch Việt Nam - bênh viện Bach Mai,

${ }^{3}$ Trung tâm Thận tiết niệu và lọc máu - bệnh viện Bach Mai.

Chịu trách nhiệm chính: Sat Chanthy

Email: chanthysat15@gmail.com

Ngày nhận bài: 16.9.2021

Ngày phản biện khoa học: 12.11.2021

Ngày duyệt bài: 22.11.2021
}

renal failure undergoing dialysis at Bach Mai hospital. Bach Mai hospital and did not have an acute desease. Results: Mean age was $54.4 \pm 12.7$ years old; the proportion of women is higher than that of men $(58.8 \%$ versus $41.2 \%)$; most had dialysis $5-10$ years $(35.3 \%)$ and more than 10 years $(35.3 \%)$. The rate of arrhythmias on the 24-hour Holter EKG (80.4\%): supraventricular arrhythmias (single atrial ventricular tachycardia: 41.2\%; double cluster atrial ventricular tachycardia: $15.7 \%$, sinus tachycardia $\geq$ ) $50 \%: 3.9 \%$, paroxysmal supraventricular tachycardia: $5.8 \%$, atrial fibrillation: 9.8\%); ventricular arrhythmias (doubleventricular ventricular rate: $11.8 \%$, tripartite: $7.8 \%$, varied, complex: $7.8 \%$, double beam, triple beam: $5.9 \%$, R/T pattern: $3.9 \%$, unstable ventricular tachycardia: $6.9 \%$ ). The rate of arrhythmia is higher in the group with hypertension, diabetes, anemia. Conclusions: The high rate of arrhythmias in patients on hemodialysis is related to hypertension, anemia and electrolyte disturbances.

Keywords: chronic kidney disease, hemodialysis, arrhythmia, holter 24 hour

\section{I. ĐĂT VẤN ĐỀ}

Tại Việt Nam, ước tính có khoảng gần 6 triệu người dân đang mắc bệnh thận (chiếm 6,73\% dân số), trong đó 80.000 người chuyển sang giai đoạn cuối cần điều trị thay thế thận. Trong đó, lọc máu chu kỳ là phương pháp hiệu quả điều trị thay thế thận; tuy nhiên, có nguy cơ gây ra nhiều tai biến, đặc biệt các tai biến về tim mạch.

Rối loạn nhịp là rối loạn thường gặp trên bệnh nhân lọc máu chu kỳ. Tỷ lệ rối loạn nhịp từ $9 \%$ đến $21 \%$ ở bệnh nhân bệnh thận mạn và tăng tới $13 \%$ đến $27 \%$ ở bệnh nhân lọc máu chu kỳ․ Nghiên cứu của tác giả Hoàng Viết Thắng ${ }^{2}$ năm 2010 trên 31 bệnh nhân loc máu chu kỳ được theo dõi trên holter điên tim cho thây có 38,7\% bệnh nhân có nhịp chậm xoang, 80,6\% nhịp nhanh xoang, $12,9 \%$ nhịp nhanh trên thất, 9,7\% nhịp nhanh thất.

Rối loạn nhịp trên bệnh nhân lọc máu chu kỳ có liên quan đến tăng nguy cơ tử vong trên nhóm bệnh nhân này. Đặc biệt, có đến $25 \%$ bệnh nhân lọc máu đột tử, trong đó có $26,9 \%$ được cho là có liên quan đến rối loạn nhịp ${ }^{3}$. Vì vậy, cần được chẩn đoán và điều trị kịp thời. Tuy 